\title{
La comunicación en tres casos de acoso laboral ${ }^{*}$
}

\section{Comunication in three cases of mobbing}

\author{
Ingrid Carolina Gómez** \\ Lina Marcela Hernández \\ Universidad del Valle, Colombia \\ Recibido: 7 de julio de 2013 \\ Revisado: 3 de septiembre de 2013 \\ Aceptado: 1 de noviembre de 2013
}

\section{Resumen}

La investigación tuvo como objetivo identificar elementos y dinámicas de la comunicación, relacionados con la interrupción, distorsión o ruptura de esta, también la descalificación y desacreditación, la denigración e insinuaciones hostiles y la ruptura de los contactos sociales en tres casos de acoso laboral; se partió de un abordaje cualitativo de tipo exploratorio descriptivo. Se aplicó una entrevista semiestructurada construida a partir de categorías de análisis previamente establecidas a los tres participantes quienes habían cumplido con los criterios para acoso laboral, de acuerdo al Cuestionario Leymann (LIPT: Leymann Inventory of Psychological Terror). Durante las entrevistas emergió la categoría estrategias de afrontamiento como elemento relevante para el manejo de la problemática. Se encontró que la comunicación se caracteriza por ser una comunicación verbal abusiva que no queda registrada en ningún soporte físico, salvo en los registros internos y emocionales de las personas que los experimentan y que en las organizaciones las comunicaciones interpersonales y grupales han llegado a niveles precarios 
en los que predomina la agresividad verbal y no verbal, el aislamiento y la falta de intervención efectiva por parte de instancias de dirección.

Palabras clave: mobbing, acoso laboral, comunicación, estrategias de afrontamiento.

\begin{abstract}
The research aimed to identify elements and dynamics of communication related to the interruption, distortion or breakdown of communication, disqualification and decertification, vilification and hostile overtones and rupture of the social in three cases of workplace harassment contacts; the design was a descriptive exploratory qualitative approach. A semi-structured interview was applied, built from previously established categories of analysis, to three participants meeting the criteria for workplace harassment on the LIPT (Leymann Inventory of Psychological Terror). During interviews, the coping strategies category emerged as a relevant element for the management of the problem. Communication was found to be abusive verbal communication that is not recorded in any medium, except in emotional and internal records of people who experience it. Interpersonal and group communications have become precarious, with dominant verbal and non-verbal aggressiveness, isolation and lack of effective intervention by management.
\end{abstract}

Keywords: Mobbing, communication, coping strategies.

El acoso laboral es definido como una conducta en la que uno o más miembros de una organización agreden, hostigan y acorralan de manera verbal y psicológica a un compañero de trabajo (Crawshaw, 2009; Leymann, 1996; Zapf y Einarsen, 2005). Se considera un modo de violencia ejercida de forma generalmente encubierta y que tiene efectos potencialmente graves sobre la salud de los acosados, al producir sensación de aislamiento e indefensión y minar profundamente la autoestima (Orduz, 2006). Igualmente, afecta a las organizaciones y a la sociedad en general.

El interés por el tema del acoso laboral comenzó a cobrar relevancia en los años 80 , cuando el investigador sueco Leymann -uno de los pioneros en la investigación de esta problemática- acuñó el término mobbing para describir un fenómeno que ocurría al interior de las empresas, y que tenía que ver con el sometimiento de una persona a un proceso sistemático de estigmatización y privación de sus derechos civiles. Plantea que la mayoría de las veces esta destructiva (in)comunicación frecuentemente se realiza de un modo muy cuidadoso, sofisticado (no deja pruebas tan- gibles), lo que no disminuye, al contrario, multiplica su efecto estigmatizador. Leymann (1990b, 1996) describe el fenómeno caracterizándolo especialmente por una comunicación hostil, carente de ética que uno o unos pocos individuos dirigen principalmente contra un único individuo, quien, a consecuencia de ello, es arrojado a una situación de soledad e indefensión prolongada, a base de acciones de hostigamiento frecuentes y persistentes (al menos una vez por semana) y a lo largo de un prolongado periodo (al menos durante seis meses). Como consecuencia de la alta frecuencia y larga duración de estas conductas hostiles, tal maltrato se traduce en un enorme suplicio psicológico, psicosomático y social.

Otro pionero en el estudio de esta problemática, Stale Einarsen (Einarsen, 1999; 2000; Einarsen, Raknes y Mattiesen, 1994; Einarsen, Hoelb y Notelaers, 2009), sostiene que aunque en varios países se han acuñado distintas terminologías para referirse al fenómeno, entre ellas bullying, work harassment, scapegoating, victimization; el núcleo central de todos estos términos es la frecuencia y repetición de los actos negativos. 
Para Hirigoyen (1999), psicoanalista francesa que ha estudiado el fenómeno en el ámbito empresarial, el acoso en el lugar de trabajo se entiende como cualquier manifestación de una conducta abusiva y especialmente, los comportamientos, palabras, actos, gestos y escritos que puedan atentar contra la personalidad, la dignidad, o la integridad física o psíquica de un individuo, o que puedan poner en peligro su empleo, o degradar el clima de trabajo. Incluye además, insultos directos, críticas constantes y recalcitrantes sobre el trabajo del acosado y sobre su vida privada; amenazas verbales, incomunicación, calumnias, rumores falsos, ridiculización y comentarios obscenos y degradantes.

La investigación sobre acoso laboral se centró inicialmente en tratar de plantear una definición unificada del fenómeno; posteriormente, en el diseño y validación de herramientas que permiten medir su aparición y desarrollo (Alario, 2004; Camargo y Puentes, 2010; Einarsen, 1999; Einarsen et al. 2009; Fidalgo y Piñuel, 2004; González de Rivera y Rodríguez, 2003; López, Vázquez y Montes, 2009; Yaman, 2009), en las implicaciones y consecuencias a nivel individual y sobre los procesos organizacionales (Einarsen et al. 2009; Hauge, Skogsatd y Einarsen, 2009; López, Picón y Vázquez, 2008; Moreno, Rodríguez, Garrosa y Morante 2005; Pompili, Lester, Innamorati, De Pisa, Iliceto, Puccinni, Fiori Nastro, Tatarrelli y Girardi, 2008; Topa, Depolo y Morales, 2007). En los últimos años, está tomando fuerza el estudio del ciberacoso laboral, como una nueva modalidad de mayor impacto (Priviteria y Campbell, 2009).

Peralta (2009a; 2009b), anota que el análisis del acoso laboral implica valoraciones subjetivas $y$ se relaciona con dinámicas organizacionales en las que el conflicto, la presión por resultados, el estrés laboral, la incertidumbre y en general las dinámicas de la globalización y la competitividad, se han convertido en las condiciones constantes que enfrentan los trabajadores hoy en día.

La comunicación dentro de las organizaciones es un fenómeno complejo caracterizado por los procesos que se generan en el interior de las mismas y desde los sujetos que la conforman; entre otros aspectos, por el establecimiento de vínculos, la transmisión de mensajes, la interacción entre las personas, el despliegue de los poderes y conflictos. Se enmarca en los colectivos humanos y puede concebirse como el conjunto total de mensajes verbales y no verbales que se intercambian entre quienes integran una organización, entre la misma organización y su entorno. Son relevantes los flujos de comunicación ascendente, descendente y horizontal. El primero, fluye de la base a los elementos de la alta jerarquía; el segundo, avanza en sentido contrario desde la dirigencia hacia la base y el tercero, se evidencia entre los individuos con niveles jerárquicos iguales (Marín, García y Ruiz, 1999).

Berlo (1969), plantea que en las organizaciones el desarrollo de un sistema de roles supone una comunicación previa entre los miembros del sistema; a través de la adopción de un rol determinado y de la interacción, un grupo de personas se vuelve interdependiente, lo que aumenta las posibilidades de que la gente pueda trabajar junta para lograr un objetivo. La asignación de una posición, la especificación de las conductas del rol, la enseñanza de modos normativos de conducta, las "costumbres" que forman parte de un sistema, todo ello se lleva a cabo a través de la comunicación.

Sánchez (2004), señala que es pertinente destacar que en las organizaciones tienen lugar comunicaciones formales, que se estructuran a través de los medios y canales de la organización, siguen las políticas y filosofías de la entidad, están en concordancia con su identidad y son una proyección de la misma en la construcción de la imagen corporativa. La comunicación informal se encuentra por fuera de los canales instituidos, es más dinámica, incontrolable, indeterminada y generadora de rumores.

Es importante preguntarse cómo el fenómeno del acoso laboral pasa por procesos de comunicación formal e informal y cuáles son sus canales característicos y privilegiados, es así como se pueden identificar algunas definiciones del acoso laboral que mencionan de manera directa o indirecta el aspecto comunicativo de las prácticas de hostigamiento en el lugar de trabajo. 
En la definición de Leymann (1996), el aspecto comunicativo tiene un papel fundamental. Comunicación hostil y desprovista de toda ética, son los términos que utiliza Leymann para enfatizar que muchos de los comportamientos agresivos entre miembros de organizaciones de trabajo implican procesos de comunicación que lejos de ser cordiales o neutros, se caracterizan por la violencia verbal o el ocultamiento de información, los gritos y amenazas verbales, los cortes en la comunicación entre el acosado laboralmente y sus compañeros o el acosador.

En esa misma línea, las definiciones de Hirigoyen (1999) y Davenport, Distler y Pursell (1999), hablan de negativas manifiestas y humillantes a la comunicación y de críticas e injurias que se profieren en contra de la víctima y que la van destruyendo moralmente. También se emplean rumores, el descrédito público que tiene por fin último sacar a una persona de su lugar de trabajo.

Posteriormente, van apareciendo otros aspectos que se relacionan no solo con la comunicación verbal sino con la no verbal. La definición de Fornés (2002) incluye comportamientos negativos, miradas de desprecio, el hecho de interrumpir constantemente al acosado en sus exposiciones o el no dar información a la víctima o dar información contradictoria con tal de inducir a cometer errores y generar dudas. Fidalgo y Piñuel (2004) introducen el maltrato verbal y modal como componentes característicos del acoso laboral, lo que implicaría reconocer que dentro del acoso laboral tienen lugar prácticas como la difamación, rumores, la ridiculización, el imitar los gestos o la voz de la víctima, la degradación y el aislamiento físico y verbal, entre otros.

Es posible entonces afirmar que en el acoso laboral existen prácticas comunicativas puntuales que de una u otra forma posibilitan, agudizan y perpetúan este fenómeno en las organizaciones de trabajo. Incluso, se puede plantear plantear que dichas prácticas comunicativas particulares se relacionarían con la dificultad para comprobar la existencia del acoso laboral, tal como lo afirma Luna (2003), el mobbing o acoso psicológico en el trabajo es uno de los elementos de un fenómeno más amplio: la violencia en el lugar de trabajo. El concepto de violencia va más allá de la mera agresión física e incluye otras conductas susceptibles de violentar e intimidar al que las sufre. Así, la violencia en el lugar de trabajo incluiría además de las agresiones físicas las conductas verbales o físicas amenazantes, intimidatorias, abusivas.

Hirigoyen (1999) y Pasquel y De la Vega (2011), sostienen que en el acoso laboral se llevan a cabo procesos de comunicación específicos. La comunicación se deforma con el objeto de utilizar al otro, para que siga sin comprender nada. La violencia transpira a través de las insinuaciones, las reticencias y lo que se silencia.

Teniendo en cuenta que en el acoso laboral, la comunicación se pone en marcha para utilizar al otro, para confundirlo y manipularlo, y además se apela a rechazar la comunicación directa, deformar el lenguaje, mentir, usar el sarcasmo, la burla, el desprecio y la paradoja, se plantea la pregunta: ¿cuáles son los elementos y dinámicas de la comunicación relacionadas con la interrupción, distorsión o ruptura de esta, la descalificación y desacreditación, la denigración e insinuaciones hostiles y la ruptura de los contactos sociales en tres casos de acoso laboral?

\section{Método}

\section{Tipo de investigación}

La investigación es de carácter exploratorio descriptivo, desde un abordaje cualitativo.

\section{Participantes}

Dos mujeres y un hombre con vínculos contractuales en la modalidad de empleo en el momento de presentarse el fenómeno de acoso laboral. Fueron seleccionados a partir de los resultados obtenidos en la aplicación del Cuestionario Leymann, que confirmaba su experiencia de acoso laboral. 


\section{Instrumentos}

\section{Cuestionario Leymann}

El Cuestionario Leymann (LIPT: Leymann Inventory of Psychological Terror), utilizado ampliamente en la medición y evaluación del mobbing, consta de 45 ítems que evalúan si una persona ha sido objeto o no de acoso psicológico u hostigamiento en su lugar de trabajo. Fue aplicado de manera virtual, a través de la herramienta Google Docs.

\section{Entrevista semiestructurada}

La entrevista semiestructurada, con preguntas abiertas, se construyó a partir de las categorías de análisis establecidas previamente (ver Tabla 1) y por otro lado, teniendo como referencia el Cuestionario de Leymann (LIPT: Leymann Inventory of Psychological Terror).

Tabla 1.

Categorías de Análisis.

\begin{tabular}{|c|c|}
\hline Categorías & Indicadores \\
\hline $\begin{array}{l}\text { Interrupción, distorsión o ruptura } \\
\text { comunicación }\end{array}$ & $\begin{array}{l}\text { Rechazo de la comunicación directa } \\
\text { Deformaciones del lenguaje } \\
\text { Mentira, sarcasmo y paradoja al dirigirse a la víctima } \\
\text { Interrupciones inconstantes cuando la víctima habla } \\
\text { Se ignora a la víctima cuando habla }\end{array}$ \\
\hline Descalificación y desacreditación & $\begin{array}{l}\text { Ataques a la calidad del trabajo } \\
\text { Desprecio hacia las iniciativas, ideas o propuestas } \\
\text { Emisión y circulación de rumores falsos o infundados sobre la víctima de } \\
\text { acoso } \\
\text { Evaluación parcial, injusta y malintencionada de su trabajo o resultados } \\
\text { Exageración sobre sus fallos y errores }\end{array}$ \\
\hline Denigración e insinuaciones hostiles & $\begin{array}{l}\text { Ridiculización de la víctima } \\
\text { Evasión del contacto visual } \\
\text { Miradas de rechazo y desprecio } \\
\text { Burlas y desprecios } \\
\text { Amenazas verbales } \\
\text { Tratos denigrantes } \\
\text { Insultos, comentarios obscenos y degradantes } \\
\text { Comentarios sobre su estado mental }\end{array}$ \\
\hline Reputación personal & $\begin{array}{l}\text { Calumnias y murmuraciones soterradas } \\
\text { Críticas y ataques sobre su vida privada, religión, familia, costumbres }\end{array}$ \\
\hline
\end{tabular}

\section{Procedimiento}

Inicialmente, fueron contactadas 7 personas a las cuales se aplicó el Cuestionario Leymann; solo tres de ellas cumplieron los criterios establecidos para acoso laboral y se procedió a realizar las entrevistas, las cuales fueron grabadas en medio digital, previo consentimiento informado; se analizó la información de acuerdo al análisis de contenido por categorías según Piñuel (2002). Luego de segmentar cada una de las entrevistas en una matriz de categorías de análisis, se procedió a crear un cuadro general para verter allí la información de las tres entrevistas de forma paralela por cada una de las categorías de análisis planteadas previamente. La categoría Estrategias de afrontamiento, emergió a partir de los hallazgos de las entrevistas y está relacionada con aquellos mecanismos y acciones emprendidas por los sujetos ante la situación de acoso laboral. 


\section{Resultados}

\section{Interrupción, distorsión o ruptura de la comunicación}

En esta categoría están presentes una serie de manifestaciones verbales, en lo que se refiere a recursos como el sarcasmo, mentira o las interrupciones y no verbales, como rechazar el contacto o evitarlo, golpear, usar tonos particulares, gestos, lenguaje corporal.

Pues horrible todo, o sea, gestos, se sentía una agresividad, pero al máximo, y todo era agresivo, como una violencia. Además de las puyas que tiraba. De todo (P3).

Es que el tono de ella es bien especial. Era sarcástica, horrible. Si me hablaba como queriendo ridiculizarlo a uno (P3).

P2 refiere principalmente episodios relacionados con el rechazo de la comunicación directa y el ignorar al otro cuando habla, pero especialmente conectados con la exclusión de espacios de encuentro o encuentros comunes dentro de la organización.

Esos dos años fueron horribles, no Dios mío, era una cosa, la otra... a mi mis compañeros, nadie se atrevía como a hablar conmigo, la gente volteaba para no mirarme, para no saludarme (P2).

A partir de lo que pasó no había comunicación, no había absolutamente nada, es más yo llegaba y saludaba y no me respondían el saludo (P2).

Por otra parte, emergen componentes fundamentales de la comunicación no verbal que dan cuenta de algunas de las interacciones comunicativas presentes en el fenómeno de acoso laboral, y aquí las narraciones de P1 aportan elementos para ilustrar este planteamiento, pues describe situaciones en las que la violencia, la intimidación y la agresión se ejercen mediante los gestos, el tono, los golpes y el tirar objetos.

El tono, el lenguaje corporal, los golpes a la mesa, uff es que los golpes a la mesa y los azotes a la puerta eran frecuentes y eso intimida y genera... además que esa oficina la compartían muchas personas, entonces yo no sé porque esa mesa nunca se partió. Porque era todo el tiempo dándole a la mesa. Además no solamente cuando discutía conmigo. $Y$ a él como lo vaciaban tanto, entonces él se 'emputaba' y entonces él nos intentaba contar a todos, subía la voz y empezaba a azotar todo, así no estuviera puto conmigo (P1).

\section{Descalificación y desacreditación}

En esta categoría aparecen manifestaciones verbales emitidas directa o indirectamente por uno o varios miembros de la organización para agredir, confrontar y aislar a una persona de forma específica. Directamente, cuando son dirigidos por una persona hacia otra; indirectamente, cuando se emiten en círculos o corrillos y llegan a oídos de la persona implicada. Los tres Participantes refieren ataques a la calidad del trabajo, evaluación parcial, injusta y malintencionada de su trabajo o resultados, exageración sobre sus fallos y errores. P1 relata hechos relacionados con el desprecio hacia las iniciativas, ideas o propuestas y manifiesta haber recibido críticas directas sobre su capacidad laboral, sus propuestas o evaluaciones desmedidas de sus errores.

En algún momento el jefe dijo que el trabajo que yo hacía lo podía hacer una muchacha de servicio (P1).

A mí me cortaron las alas prácticamente al principio, yo nunca volví a proponer algo como nuevo. $Y$ por parte de $A^{*}$, pues prácticamente no me dejaba hablar (P1).

Un día que dije, es que puedo entregar para tal día me dijeron que tenía el cerebro podrido, a una vez que yo porque sabía una cosa y yo dije que por una experiencia que tuve me dijeron que yo era un pretencioso, o que qué era lo que yo me creía (P1).

P2 y P3 narran episodios de emisión y circulación de rumores falsos o infundados sobre ellas. 
Los rumores eran que yo era la que no quería trabajar, la que no quería hacer, la que de pronto la estaba persiguiendo y que yo la había llevado de pronto hasta comisión de personal, que como me había atrevido a eso (P3).

P2 narra episodios de rumores centrados en comentarios que trascendían y circulaban entre sus compañeros de trabajo. Se le calificó de 'bruta' por ser incapaz de desarrollar una labor para la cual manifiesta no haber sido capacitada, ni haberla desarrollado de manera previa.

Por ejemplo me pusieron a hacer encuestas y... yo tenía que tabular todas las encuestas, pues la verdad a mí no me capacitaron para eso, yo no tenía ni idea. Una de las jefes que me asignaron se molestó cuando le dije que no sabía hacerlo, ella decía "esa vieja bruta no sabe tabular" y eso a mí me llegó, porque bruta, pero a mí no me enseñaron si a mí me hubieran ensenado había podido aprender (P2).

Ellos decían que yo quería acabar con la empresa, yo me di cuenta de eso, decían que yo era un mal elemento (P2).

P3 narra episodios de rumores que trascendían y circulaban entre sus compañeros de trabajo.

Pero es que era la comidilla, que uno pasaba y estaban como en el cuchicheo que lo miraban a uno, era eso. Pero igual como yo me alejé, y eso se volvió un hervidero (P3).

\section{Denigración e insinuaciones hostiles}

Para esta categoría se destacan lo verbal y lo no verbal, se hacen presentes y son empleados por los agresores para referirse a la víctima, ridiculizándola, amenazándola, haciéndola objeto de tratos denigrantes y así mismo para quebrantar los vínculos, mencionando agresiones, intentos de ridiculización, amenazas verbales, burlas, denigración, insultos y miradas de desprecio o evasión del contacto visual.

P1 hace énfasis en los insultos y denigraciones de los que fue objeto y que se referían a su capacidad intelectual, su origen y cultura.
Cerebro podrido, me marcó mucho. Cultura tropicana, subdesarrollados, atrasados, sudamericanos. Gritos, golpes, el intento de degradación, eh umm... los sarcasmos frente a mi origen, las veces que me decían bobo directamente, una vez que me dijeron que tenía el cerebro podrido (P1).

De $A^{*}$ fueron innumerables las veces que golpeó la puerta o las sillas. Un día que me senté se me paró al lado y empezó a tirar todos los papeles que yo tenía ahí, y que entonces que y a gritarme impresionante y otros compañeros nos miraban (P1).

Yo tengo epilepsia... $A^{*}$ se enteró e intentó demostrarles y decirles que yo no era la persona más adecuada para ocupar el puesto porque tenía eso (P1).

Sí. ehh sí, pero sobretodo eran unos memorandos con mayúsculas diciendo que él iba a tomar medidas más duras y todo eso, pero eso no pasaba de allí (P1).

P2 señala que recibió amenazas telefónicas en su lugar de trabajo y en su apartamento y que constantemente era atemorizada a través de comentarios dentro de la empresa. Se le insultaba con palabras obscenas, se le despreciaba e incluso se evitaba el contacto visual.

Me ignoraban todo el tiempo, pero si en algún momento daba la casualidad de que yo iba pasando me tiraban la puerta, parecían niños chiquitos. Así de ese tamaño (P2).

¿Vieja hijueputa hasta cuándo va a estar allí? Y si su marido vuelve, a su marido y a usted los vamos a matar (P2).

Recibí unas llamadas diciendo que si yo no me iba de la empresa y que si mi esposo no se iba de la empresa me iban a matar a mí, a él y a toda mi familia, recibí varias llamadas. Luego también nos llamaron aquí al apartamento, ellos pensaban que yo iba a salir corriendo (P2).

P3 indica que se le gritó, se le trataba con agresividad, miradas burlonas y de desprecio y rechazo general. 
$Y$ ahí fue donde me pegó un grito que eso no se me quitó, yo me acuerdo que pasó gente, yo no me acuerdo quién, pero esa parte para mí fue lo más duro. Me pegó un grito, me dijo que yo que estaba pensando, que dejara de ser tan grosera, que por qué tenía que decirle a ella esas cosas, que ella por qué tenía que estarle mandando copia de las cosas (P3).

Si la agresividad, era una cosa o sea era como, solo pensar que pasaba esa puerta, igual seguíamos en la misma oficina, sentía esa agresividad. Tiraba la puerta, entraba, salía y yo en mi espacio. Mi espacio (P3).

\section{Reputación personal}

En esta categoría predominan también los componentes verbales que se usan específicamente para minar la reputación de una persona dentro de la organización, y como se evidencia en las respuestas de los participantes, desencadenar situaciones de mayor aislamiento y de agudización de una comunicación hostil, agresiva y deteriorada.

Me dijeron que yo era un bobo porque jugaba fútbol. Lo que yo hacía era tratar de que mi vida personal fuera invisible para ellos y aun así se enteraron de que yo tenía novia (P1).

Algo que no había dicho es que a nosotros nos espiaban, nos chuzaban los teléfonos, el correo y el Skype, eso me parecía cierto abuso a la intimidad, era con el pretexto de que uno no fuera a sacar ninguna información, igual ahí no había nada que llevarse, entonces, pero en algún momento por ejemplo la hermana de Don $F$, que era accionista de la empresa, un día me escribió un correo diciéndome que se había contado lo que yo había escrito, y eso a mí me generó uy como que se me metieron a la cocina (P1).

Claro, los rumores, ella se incapacita porque quiere, ella no, ella es hipocondriaca porque ella se enferma para no venir a trabajar, ella hace lo que se le da la gana porque nadie sabía que mientras yo estaba incapacitada, yo estaba trabajando, desde mi casa trabajaba (P3).

\section{Estrategias de afrontamiento}

Esta categoría emergió de las narraciones de los participantes relacionada con todas aquellas acciones emprendidas por ellos ante la situación de acoso laboral. P1 fue el único que no buscó ayuda profesional, conversaba la situación con algunos de sus compañeros y amigos por fuera de la organización y buscaba constantemente empleo.

Bueno, de alguna u otra manera comentaba con otra persona el episodio sucedido y eso ya era como cierta catarsis... también generaba la solidaridad del otro, pero eso generaba cierto efecto. A veces me ponía a mirar periódicos como a descargarme (P1).

P2 y P3 buscaron ayuda médica y psiquiátrica para enfrentar la situación de acoso laboral; como mecanismos de afrontamiento P1 y P2 empleaban la lectura; P2 y P3 se aislaron y silenciaron.

Pues digamos el psiquiatra siempre me decía que tenía que pensar en otra cosa, que tratara de no como que no, sobretodo porque yo por las noches no dormía, me decía que no pensara en lo que me pasaba de día, que pensara que había un futuro, que tenía que pensar en otra cosa. Es que a uno le dicen muchas cosas pero es muy fácil decirlas pero para uno que está en su problema es difícil hacer lo que ellos dicen. Es difícil (P2).

O sea eran sesiones muy duras, me dio dos veces a la semana, me colocó diagnósticos acoso laboral, estrés y otra palabra por acoso laboral. Ella me decía que si yo necesitaba me podía dar más incapacidades, pero yo le decía que yo necesitaba trabajar, pero entonces yo estaba lleno cada ocho días hasta que me fue soltando, cada quince, cada mes (P3).

Yo antes tenía amigas, a mí después de eso, me volví sola. Porque yo digo que amigos ni amigos ni nada, eso no hay. Yo me metí, como le dijera, no quería nada, no quería salir, sino solo estar metida en lo que me pasaba, como que iba a hacer yo (llanto). Y mi escape era la lectura. Yo me metía en el libro como para olvidar todo lo que me estaba pasando (P2). 
En el caso de P3, sus respuestas emocionales aún reflejan rabia y odio, miedo, angustia, resentimiento y tristeza.

\section{Discusión}

A nivel general, puede inferirse que las respuestas de los tres participantes dan cuenta de organizaciones en las que las comunicaciones interpersonales y grupales han llegado a niveles precarios en los que predomina la agresividad verbal y no verbal, el aislamiento y la falta de intervención efectiva por parte de instancias de dirección. Organizaciones en las cuales, más allá de las estructuras visibles, los organigramas formales y los canales de comunicación establecidos, predominan complejas interacciones marcadas por una(s) personas(s) que deciden atacar a otra(s), y para ello se valen de manifestaciones que pasan por lo verbal y lo no verbal, que entorpecen el desarrollo de las tareas y funciones, que enrarecen los ambientes laborales y que generan profundas huellas en las relaciones de trabajo, sociales e interpersonales, además de impactos directos sobre la salud de quienes son víctimas del acoso laboral e impactos indirectos sobre los demás miembros de los grupos de trabajo.

Es importante destacar que el acoso laboral no impacta o involucra únicamente a dos personas o a un grupo de personas dentro de una organización, sino que afecta todo el sistema de relaciones, deteriora el entorno y genera desde compasión, empatía o indiferencia, hasta la sensación de desconfianza, inestabilidad e inseguridad. Todo esto sin mencionar los aspectos económicos que en muchos casos asume la organización por cuenta de las incapacidades a las que se ve abocada la persona acosada laboralmente.

Puede plantearse, que la responsabilidad de una persona que acosa a otra en una organización se complementa e incluso se fomenta gracias a la falta de compromiso organizacional para la toma de acciones y decisiones concretas.

De acuerdo con González de Rivera (2002), el factor catalítico clave en el inicio y desarrollo del acoso laboral es la organización, facilitando comportamientos violentos o por el contrario tomando las medidas concretas para que no se produzcan. Igualmente sucede con los miembros de la empresa o del grupo de trabajo, que pueden comportarse de forma colaboradora, indiferente, permisiva, o encarar el fenómeno de forma directa.

Morelo (2009), sostiene que la empresa no es solo el espacio donde el acoso laboral tiene lugar o un simple marco que define la relación social jefesubordinado, sino un sistema estructurante de la comunicación y por lo tanto, del propio proceso de agresión. Existiría un modo de ser y de actuar corporativos, vinculado a unas características materiales determinadas, tendente a producir este tipo de comportamientos, por lo que los contextos en los que estos muestran su razón de ser pueden entenderse, al menos parcialmente, como cultura para el acoso.

Este sistema estructurante de la comunicación señalado por Morelo se va escalando poco a poco, como lo concluyen los relatos de los tres participantes. Al revisar sus narraciones, se evidencia que de prohibiciones verbales explicitas para entablar contactos, se va pasando al sarcasmo, golpes a objetos e incluso a agresiones físicas, al contacto agresivo e irrespetuoso, no únicamente a través de las palabras y los gestos sino que llega a traducirse en ataques contra la integridad personal.

Según Morelo (2009) y Aramburu-Zabala (2002), la distorsión de la comunicación entre los trabajadores interfiere sistemáticamente en la ejecución de las tareas, dado que el acoso laboral influye en la disminución de la cantidad y calidad del trabajo, y dificulta el rendimiento de los equipos al producir una distorsión en los mecanismos de feedback y comunicación.

Sánchez (2004), ha señalado que en las organizaciones tienen lugar comunicaciones formales e informales; las informales están al margen de los canales instituidos y son menos fáciles de controlar, seguir o evaluar, y por lo tanto son los canales predilectos, aunque no exclusivos para que ocurra el acoso laboral. 
Al hacer explicita la prohibición de entablar contacto con una persona dentro de una organización, es claro que se está formalizando y de alguna manera validando dicha conducta al hacer pública la intención de no dirigirle la palabra a la persona que está siendo acosada. Aunque esa prohibición no se realice por escrito y por lo tanto no exista un registro físico, el mero hecho de llevarla al nivel verbal y compartirla con otros miembros de la organización, sin que en ninguna instancia se detenga o desapruebe esa conducta, evidencia el enorme poder que tienen los procesos de comunicación en sí mismos, y la comunicación informal en este caso particular del acoso laboral.

Que ocurra el acoso laboral, es prueba de que la comunicación dentro de una organización va mucho más allá de la existencia de canales y herramientas formales como la intranet, los correos electrónicos, las carteleras, los comités o equipos de trabajo. Es evidente que en el acoso laboral hay un predominio marcado de la comunicación informal y hay que decir que esta se encuentra por fuera de los canales instituidos, es más dinámica, incontrolable e indeterminada y por lo tanto ofrece un contexto para desatar el acoso sin que haya mayores peligros para el acosador de ser descubierto.

Pareciera que la comunicación interna en las organizaciones fuese un escenario privilegiado para la puesta en marcha de fenómenos como el acoso laboral, porque aunque dichas organizaciones crean a nivel formal pautas comunicativas de respeto, buen trato y tolerancia; en la práctica, y ante la ausencia de liderazgos sanos y efectivos, se desencadenan interacciones comunicativas dañinas y cuyo crecimiento tiene el efecto bola de nieve.

Al respecto, Hirigoyen (1999) sostiene que en el ámbito empresarial, la violencia y el acoso nacen del encuentro entre el ansia de poder y la perversidad. Las grandes perversiones destructivas son menos frecuentes, pero las pequeñas perversiones cotidianas se consideran triviales. Aunque el acoso se produzca horizontalmente (un compañero agrede a otro), los superiores en la jerarquía no suelen intervenir ni prestarle demasiada aten- ción. En realidad, el conflicto se genera porque la empresa se niega a entrometerse: "ya son ustedes mayorcitos para arreglar solos sus problemas". El acosado no siente que le defiendan. A veces, incluso percibe un abuso por parte de los que asisten a esta agresión sin intervenir, pues sus superiores casi nunca proponen directamente una solución: "ya lo veremos más tarde”.

Puede decirse que el acoso surge más fácilmente en ambientes laborales donde predomina el estrés y la mala comunicación. Hirigoyen considera que existen formas de organización empresarial perversas que "se muestran incapaces de conseguir que, en su seno, se respeten los derechos mínimos de las personas" (p. 60).

Por otra parte, en los tres casos analizados se evidencia un quiebre de la comunicación que está enmarcado en estructuras de comunicación organizacional débiles, en los cuales los canales e instrumentos de comunicación son precarios e ineficaces y los liderazgos sencillamente deciden desatender cualquier pedido de ayuda por parte de las personas acosadas laboralmente.

Las narraciones de los tres sujetos muestran que gran parte, por no decir que todo el proceso de acoso laboral, pasa necesariamente por la comunicación. Las palabras agresivas y pronunciadas de forma displicente, los gritos, rumores, golpes y azotes, las miradas de desprecio, la evasión de los contactos visuales son signos característicos de la comunicación verbal y no verbal. También son evidencias de que dentro del acoso laboral predomina una comunicación caracterizada por conductas dañinas de hostigamiento. El mismo Morelo explica que la comunicación del hostigamiento viene definida, de modo pragmático: consiste en una sucesión más o menos estructurada de mensajes cuya finalidad es producirlo, para disminuir o derribar al receptor de la misma -sojuzgarlo y mantenerlo bajo un control personal absoluto de todas sus conductas o, directamente, expulsarlo de la organización-.

En los tres casos, la comunicación se caracteriza especialmente por la frialdad en los mensajes entre el acosador y el acosado, la dureza y extrema brevedad de los mismos y porque se lleva a cabo 
principalmente a través de canales informales de interacción.

Uno de los aspectos fundamentales en el desarrollo del acoso laboral, está representado en la puesta en marcha de los recursos de la comunicación interpersonal y grupal que el acosador hace para dominar y aplastar al otro. Estos recursos incluyen la distorsión y deformación de hechos y palabras, la crítica destructiva, rumores, mentiras, burlas, desprecios y evasión del contacto físico y visual, entre otros. También hacen parte de este aparataje comunicativo el uso marcado del lenguaje verbal ambiguo y confuso, que genera confusión y desorientación, así como una preferencia de los aspectos no verbales como los gestos, las miradas, el tono agresivo, sarcástico o displicente que en su conjunto sirven para marcar y ahondar la distancia.

Hay que señalar además que otro de los componentes característicos de la comunicación dentro del acoso laboral es el silencio de la organización. En los tres casos descritos, el rechazo a la comunicación, el ignorar a la víctima cuando habla, el rechazo y huida por parte de los colegas, la negación o invisibilización de la presencia de víctima, la prohibición de establecer contactos o conversaciones con la víctima, se entremezclan y superponen para dar lugar a un silencio que primero inicia el acosador y que de alguna manera valida el grupo y luego la organización misma al abstenerse de intervenir.

La comunicación también se deteriora y pervierte a través del silencio. Para ignorar la presencia del otro, excluirlo y dañarlo no solo se le niega a nivel físico, sino que también se interrumpe su existencia en el nivel escrito y virtual. El no responder los correos electrónicos o las peticiones escritas es muestra de que el rechazo de la comunicación si bien puede desencadenarse por una prohibición verbal, continúa cuando el acosador y las personas que están alrededor de la situación optan por no contactar a la víctima, al no tener en cuenta su presencia física, al no dirigirle la palabra y al hacer de cuenta que no se leyó o recibió alguna comunicación suya por escrito. El tema se agudiza cuando la misma organización decide mirar hacia otro lado, desatendiendo las quejas o llamados de las personas afectadas.

Si bien el silencio del que acosa directamente, de los que están alrededor y deciden no contactar a la víctima y de la misma organización, no logran la desaparición física de una persona dentro de la organización, sí deriva en su negación y exclusión, lo que la daña emocionalmente y tiene consecuencias sobre su desempeño laboral y en general sobre el propio sistema de comunicación de la organización.

Desde la perspectiva de Watzlawick, Beavin y Jackson (1989), puede decirse que el acoso laboral es casi de manera exclusiva de comunicación. Golpes a los objetos, a las puertas o miradas de desprecio, son acciones físicas que se emplean como signos del proceso y que son consideradas como asedio, dado que emiten en sí mismas mensajes de acoso. Rechazar y descalificar la comunicación no es que evite el compromiso inherente a toda comunicación, no es que se pueda huir de la comunicación o evitar la relación comunicativa.

El acoso laboral es un fenómeno en donde predominan prácticas comunicativas carentes de ética que tienen lugar en organizaciones donde los canales de comunicación son poco eficientes. Los procesos de comunicación que caracterizan los tres casos revisados permiten inferir que la comunicación se caracteriza por ser una comunicación verbal abusiva que no queda registrada en ningún soporte físico, salvo en los registros internos y emocionales de las personas que los experimentan; una comunicación no verbal que no se vale de palabras sino de acciones soterradas, gestos burlones y miradas de desprecio para destruir, cuestionar, rebajar, ignorar o humillar al otro; una comunicación que se produce dentro de organizaciones cuyos líderes son ausentes, evasivos y evitan involucrarse en el asunto y por el contrario lo relegan hasta la esfera individual, lo que pondría de manifiesto sino la complicidad, por lo menos la negligencia de algunas organizaciones frente al fenómeno; una comunicación que se da en el nivel informal, lo que facilita la violencia y agresividad, ya que se trata de interacciones que se dan por fuera de los canales instituidos y que son dinámi- 
cas, incontroladas e indeterminadas; una comunicación que se alimenta y se vale de componentes verbales y no verbales, expresiones e interpretaciones de los actores involucrados directa e indirectamente. Es una comunicación ambivalente, que confunde mediante los silencios, las rupturas y rechazos, las descalificaciones, los dobles sentidos, los mensajes incoherentes y confusos.

Es claro, que al interior de las organizaciones donde ocurren los hechos de acoso laboral, hace falta una política clara y fuerte para hacerle frente a este tipo de fenómenos, partiendo de la consideración de que la empresa es responsable de lo que sucede con sus colaboradores. La organización no es un espacio donde ocurre el acoso sino que es un sistema vivo que da estructura a la comunicación y por ende a la agresión, el hostigamiento y el acoso y eso daría lugar a considerar que hay unos modos organizacionales que sino originan por acción, por lo menos dan pie por omisión a este tipo de fenómenos.

Se pueden desarrollar estudios posteriores, sobre la exploración de los procesos de comunicación desde la perspectiva del acosador o un abordaje desde los grupos de trabajo donde se generan casos de acoso laboral. Sería enriquecedor por ejemplo, emplear técnicas de simulación para evaluar las respuestas de las personas frente a las situaciones de acoso.

Para una comprensión global, el acoso laboral debe ser leído teniendo en cuenta las realidades actuales del trabajo, en las cuales se visibilizan claras tendencias a la deslaboralización y flexibilización por un lado y por el otro, la coexistencia con formas tradicionales y contractuales de trabajo. De allí la necesidad de que la Psicología del Trabajo y las Organizaciones se pregunte sobre las tendencias y coexistencias de formas y organizaciones de trabajo, y de esta manera, promover la construcción de relaciones recíprocas así como de explicaciones y prácticas pertinentes, particularmente en lo relativo a la gestión de Recursos Humanos. Sería mediante esas reflexiones y relaciones propuestas por Rentería (2009), que la Psicología del Trabajo y las Organizaciones podría ayudar a que las organizaciones de trabajo comprendieran y afrontaran, con mejores herramientas, fenómenos que como el acoso laboral impactan al trabajador, a las organizaciones y a la sociedad.

\section{Referencias}

Alario, S. (2004). El acoso institucional o Mobbing: Presentación de la evaluación y tratamiento en dos casos crónicos. Cuadernos de Medicina Psicosomática y Psiquiatría de Enlace, (6970), 126-135.

Aramburu-Zabala, L. (2002). Respuesta al acoso laboral. Programas y estrategias. Cuadernos de Relaciones Laborales, 20(2), 337-350.

Berlo, D. (1969). El proceso de comunicación. Introducción a la teoría y a la práctica. Buenos Aires: Editorial El Ateneo.

Camargo, J., y Puentes, A. (2010). Rasgos de personalidad y autoestima en víctimas de acoso laboral. Revista Diversitas: Perspectivas en Psicología, 6(1), 51-64.

Crawshaw, L. (2009). Workplace Bullying? Mobbing? Harassment? Distraction by a Thousand Definitions. Consulting Psychology Journal: Practice and Research, 61(3), 263-267.

Davenport, N., Distler, R., y Pursell, G. (1999). Mobbing. Emotional abuse in the American workplace. Ames: Civil Society Publishing.

Einarsen, S., Raknes, B., y Mattiesen, S. (1994). Bullying and Harrasment at work and their relationships to work environment quality: an exploratory study. European Work and Organizational Psychologist, 4(4), 381-401.

Einarsen, S. (1999). The nature and causes of bullying at work. International Journal of Manpower, 20(1-2), 16-27.

Einarsen, S. (2000). Harassment and bullying at work: a review of the scandinavian approach. Aggression and Violent Behavior, 5(4), 379401. 
Einarsen, S., Hoelb, H., y Notelaers, G. (2009). Measuring exposure to bullying and harassment at work: Validity, factor structure and psychometric properties of the Negative Acts Questionnaire-Revised. Work \& Stress: An International Journal of Work, Health \& Organisations, 23(1), 24- 44.

Fidalgo, A., y Piñuel, I. (2004). La escala Cisneros como herramienta de valoración del mobbing. Psicothema, 16(4), 615-624.

Fornés, J. (2002). Mobbing: La violencia psicológica como fuente de estrés laboral. Enfermería Global, 1, 1-10.

González de Rivera, J. (2002). El maltrato psicológico. Cómo defenderse del mobbing y otras formas de acoso. Madrid: Espasa Calpe, Colección Espasa Práctico.

González de Rivera, J., y Rodríguez, M. (2003). Cuestionario de estrategias de acoso psicológico: el LIPT-60 (Leymann Inventory of Psychological Terrorization) en versión española. Psiquis, 24(2), 59-69.

Hauge, L., Skogsatd, A., y Einarsen, S. (2009). Individual and situational predictors of workplace bullying:Why do perpetrators engage in the bullying of others? Work \& Stress: An International Journal of Work, Health \& Organisations, 23(4), 349-358.

Hirigoyen, M. (1999). El Acoso Moral. El Maltrato Psicológico en la Vida Cotidiana. Barcelona: Paidós.

Leymann, H. (1990b). Mobbing and psychological terror at workplaces. Violence and Victims, 5(2), 119-126.

Leymann, H. (1996). Contenido y Desarrollo del Acoso Grupal/moral ("Mobbing”) en el Trabajo. European Journal of Work and Organizational Psychology, 5(2), 165-184.

López, M., Picón, E., y Vázquez, P. (2008). Estudio del acoso psicológico en la universidad pública de Galicia. Revista de Psicología del Trabajo y de las Organizaciones, 24(1), 41-60.
López, M., Vázquez, P., y Montes, C. (2009). Validación de la Escala Cisneros de Mobbing al Gallego. Revista de Psicología del Trabajo y de las Organizaciones, 25(3), 231-243.

Luna, M. (2003). Acoso psicológico en el trabajo (mobbing). Madrid: Ediciones GPS.

Marín, L., García, C., y Ruiz, J. (1999). Sociología de la comunicación. Madrid: Editorial Trotta.

Morelo, A. (2009). Acoso Moral y Comunicación Interna (el caso del bossing, o acoso a cargo del jefe o sus representantes o directivos). Madrid: Universidad Complutense de Madrid.

Moreno, B., Rodríguez, A., Garrosa, E., y Morante, M. (2005). Antecedentes organizacionales del acoso psicológico en el trabajo: un estudio exploratorio. Psicothema, 17(4), 627-632.

Orduz, J. (2006). Identificación del Mobbing o Acoso Laboral en una empresa del sector industrial de Mamonal, en Cartagena. Cartagena: Universidad de San Buenaventura.

Pasquel, M., y De la Vega, N. (2011). Mobbing: el peligroso fantasma de las instituciones. Revista hospitalidad-ESDAI, 19(1), 111-144. Recuperado de http://esdaiposgrados.wordpress. com/2011/ (Alcalá \& Morell, 2011)09/14/ mobbing-el-peligroso-fantasma-de-las-instituciones-por-ma-ofelia-pasquel-alcala-y-nahumde-la-vega-morell/

Peralta, M. (2009a). El acoso laboral, mobbing: ¿un nombre nuevo para un problema viejo? En M. Aguilar y E. Rentería (edits.). Psicología del Trabajo y de las Organizaciones. Reflexiones y Experiencias de Organización, 421-443. Bogotá: Universidad Santo Tomás.

Peralta, M. (2009b). La construcción de sujetos en las nuevas realidades laborales. Reflexiones para su estudio desde la Psicología Organizacional y del Trabajo. En E. Rentería y Ma. C. Aguilar (edits.). Psicología del Trabajo y de las Organizaciones. Reflexiones y experiencias de investigación, 53-76. Bogotá: Universidad Santo Tomás. 
Piñuel, J. (2002). Epistemología, metodología y técnica del analisis de contenido. Estudios de sociolingüística, 3(1), 1-42.

Pompili, M., Lester, D., Innamorati, M., De Pisa, E., Iliceto, P., Puccinno, M., Fiori Nastro, P., Tatarrelli, L., y Girardi, P. (2008). Suicide risk and exposure to mobbing. Work, (31), 237.

Priviteria, C., y Campbell, M. (2009). Cyberbullying: The New Face of Workplace Bullying? Cyberpsychology \& Behavior, 12(4), 396- 400.

Rentería, E. (2009). De Recursos Humanos a la Psicología Organizacional y del Trabajo: reflexiones a la luz de las realidades actuales del mundo del trabajo. En Ma. C. Aguilar y E. Rentería (edits.). Psicología del Trabajo y de las Organizaciones. Reflexiones y experiencias de investigación (25-52). Bogotá: Universidad Santo Tomás.

Sánchez, F. (2004). Modelos y esquemas de comunicación. Algunos acercamientos. Medellín: Sello editorial Universidad de Medellín.
Topa, G., Depolo, M., y Morales, F. (2007). Acoso laboral: meta-análisis y modelo integrador de sus antecedentes y consecuencias. Psicothema, 19(1), 88-94.

Waztlawick, P., Beavin, J., y Jackson, D. (1989). Teoría de la comunicación humana. Barcelona: Editorial Herder.

Yaman, E. (2009). The Validity and Reliability of the Mobbing Scale (MS). Kuram ve Uygulamada Eğitim Bilimleri / Educational Sciences: Theory \& Practice, 9(2), 981-988.

Zapf, D., y Einarsen, S. (2005). Mobbing at work: Escalated Conflicts in Organizations. En S. Fox y P. Spector (Edits.). Counterproductive Work Behavior. Investigations of Actors and Targets, 237-270. Washington D.C: American Psychological Association. 